\title{
The Impact of Intellectual Capital on Smart Organization in AlBashir Hospital
}

\author{
Ikram Rashed Dawood, Shaker Jaralla Alkshali
}

To Link this Article: http://dx.doi.org/10.6007/IJARBSS/v12-i1/12092

DOI:10.6007/IJARBSS/v12-i1/12092

Received: 14 November 2021, Revised: 18 December 2021, Accepted: 01 January 2022

Published Online: 24 January 2022

In-Text Citation: (Dawood \& Alkshali, 2022)

To Cite this Article: Dawood, I. R., \& Alkshali, S. J. (2022). The Impact of Intellectual Capital on Smart Organization in AlBashir Hospital. International Journal of Academic Research in Business and Social Sciences, 12(1), 1391-1406.

Copyright: (c) 2022 The Author(s)

Published by Human Resource Management Academic Research Society (www.hrmars.com)

This article is published under the Creative Commons Attribution (CC BY 4.0) license. Anyone may reproduce, distribute, translate and create derivative works of this article (for both commercial and non0-commercial purposes), subject to full attribution to the original publication and authors. The full terms of this license may be seen at: http://creativecommons.org/licences/by/4.0/legalcode

\section{Vol. 12, No. 1, 2022, Pg. $1391-1406$}

Full Terms \& Conditions of access and use can be found at http://hrmars.com/index.php/pages/detail/publication-ethics 


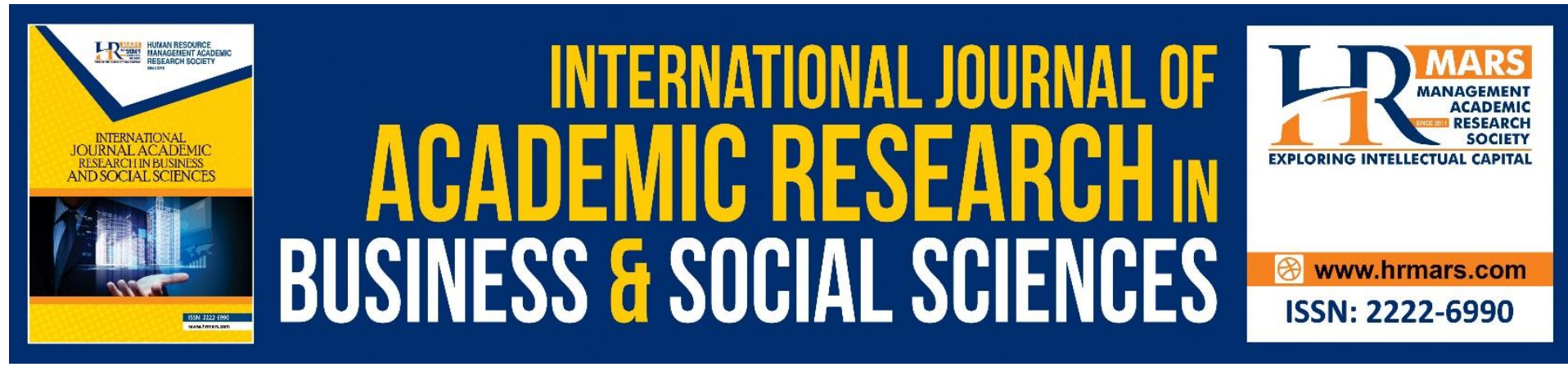

\title{
The Impact of Intellectual Capital on Smart Organization in AlBashir Hospital
}

\author{
Ikram Rashed Dawood, Shaker Jaralla Alkshali \\ The world Islamic Sciences \& Education University. \\ Email: dawoudikram@gmail.com,drshaker55@yahoo.com
}

\begin{abstract}
The study aimed to test the impact of intellectual capital (human capital, structural capital, and relational capital) on smart organization (environment understanding, continuous learning, find strategic alternatives, adaptation and collective intelligence) at Al-Bashir Hospital in Jordan. The study used the quantitative descriptive approach, where the study data were collected from hospital administrators through an electronic questionnaire that was distributed to all directors in it, and 103 questionnaires were retrieved, which were subjected to statistical analysis.

The study results indicated that they found average levels of the dimensions of intellectual capital and the dimensions of smart organization. The results also showed that there is a significant impact of intellectual capital on smart organization, and that the most influential dimensions of intellectual capital on smart organization are relational capital and structural capital.
\end{abstract}

Keywords: Intellectual Capital, Smart Organization, Albashir Hospital, Jordan.

\section{Introduction}

The business environment of the current era is witnessing great developments, as investment in the health sector is considered one of the most profitable investments, and has a high contribution to protecting the purchasing power of savings, as it is considered one of the most common economic activities among people, and the investor base in this sector in Jordan is large. Very, as the investment portfolios in this sector are large, whether in Jordan or other countries, and investment in the health sector is usually an important part of its assets with the aim of diversifying returns and risks, as it is one of the safest and most stable sectors. The health sector in Jordan plays an important role in economic growth and in the gross domestic product. This sector also contributes to creating many job opportunities. Health services are considered among the important guarantees for banks when granting loans to their clients, index of investment in this sector.

The internal and external environmental changes, developments and continuous challenges facing hospitals, require them to pay attention and focus on their intangible assets that include basic elements that may be more important than the tangible physical assets of organizations, such as cognitive and organizational capabilities, developing relations with stakeholders, patents and other assets that express Intellectual capital, which affects the 
ability of hospitals to progress and thrive. The intellectual capital in hospitals is a set of unique knowledge assets that depend on creative human minds, work requirements and systems, and the relationship with customers, which leads to the continuous production of new ideas and methods through which they achieve an added value for the hospital, support its competitive capabilities and achieve its goals, facing future risks and challenges. Which hospitals are exposed to, require efficient and effective intellectual capital capable of building smart organizations that have the skills and high capabilities that enable them to take actions and decisions in a changing environment that the organization has the ability to realize and understand, and to establish and maintain relationships with stakeholders, as well as the ability to adapt With the environment and responding to it through the presence of strategic alternatives, the organization has the ability to choose the best one, especially by using information and communication technologies and continuous learning processes for its employees, in order to achieve maximum benefit from the basic processes and automation of decision-making processes.

\section{Study Importance}

The importance of the study comes in two aspects:

- The scientific aspect: The importance of this study stems from the importance of the variables it included, as intellectual capital is one of the important administrative concepts that the researcher considers the need to research, because of its importance in helping organizations to survive and continue for business organizations. The concept of smart organizations is also considered one of the modern administrative topics in the field of business, which researchers are often interested in studying and researching for its role in the growth of organizations and helping them achieve their goals.

By reviewing previous studies, the researchers noted the lack of studies linking their variables, as studies in this field are still insufficient. Therefore, the researchers hope that this study will be a qualitative addition that enriches knowledge in the field of its variables (intellectual capital, smart organization), and contributes to filling something short of the Arab library in its field.

- The practical aspect: The practical importance of the study is the extent to which the administration of AlBashir Hospital has benefited from the results it will reach, with regard to the concept of intellectual capital, and the smart organizations of these companies.

The importance of the study also comes from the importance of the sector in which it will be applied, as the health sector is considered one of the most promising economic sectors in Jordan, in terms of its contributions to economic development. On the contrary, it was a major tributary to Jordan's economy when many other economic sectors were suffering from economic and security crises, and in terms of the dependence of most other sectors on the activity of this sector.

\section{Study Objectives}

- Identifying the level of relative importance of intellectual capital and smart organization in AlBashir Hospital.

- Identifying the impact of intellectual capital on smart organization in Al-Bashir Hospital.

- Identifying the most important dimensions of intellectual capital influencing the smart organization in Albashir Hospital. 


\section{Study Problem}

Smart organizations contribute to enhancing the sustainability of organizations in an environment characterized by continuous change at all levels, and by delving into the essence of smart organizations that focus primarily on the most important element in business organizations today, which is the human element, by focusing on their intellectual capital. The concept of smart organizations supports the work of these organizations by making them the most distinguished and most competitive. Smart organizations also enhance the organizations' ability to achieve their vision and mission for which they were established through the concerted efforts and diligence of employees, and the optimal exploitation of the human element in the organizations and the preservation of their survival and continuity.

Because of the great developments witnessed by business organizations, and with the intensification of competition between organizations working in the health sector, smart organizations have become an indicator of the extent of a healthy work environment. On the contrary, it is noted that organizations that do not have and support in their strategic and operational plans their intellectual capital. They are described as weak companies that do not have the ability to survive in the face of rapid changes and intense competition.

This study seeks to research the smart organization in AlBashir Hospital, which enables it to increase its effectiveness and efficiency in achieving its goals, and the ability to work within the dimensions of intellectual capital represented in human capital, structural capital, and customer capital. A work that encourages employees to adopt the concept of smart organizations is an urgent and important matter, as this is reflected in the flow of administrative processes from top to bottom smoothly and in a manner that increases affiliation and loyalty among employees, and this is what makes this hospital in a state of attention to the current moment, which increases its awareness of the importance of generating a culture Rational thinking through optimal and effective use of its intellectual capital.

Based on the foregoing, this study will focus on the concept of the smart organization, and the impact of intellectual capital in achieving it. Accordingly, the study problem can be determined by the following question:

- What is the impact of intellectual capital on smart organization in Al-Bashir Hospital?

\section{Theoretical Background Intellectual Capital}

The beginnings of the emergence of intellectual capital go back to the seventeenth century, and this concept entered the field of management at the beginning of the nineties of the last century. The concept of intellectual capital is based on the intangible assets of the organization, and its human resources that have the necessary skills, knowledge and experience, supported by organizational and material capabilities and external relations, which in turn gives the organization the ability to improve performance, achieve superiority, competitive advantage, creative strategic development and achieve profits, through creativity, innovation and contributions intellectual. Intellectual capital is often described as the difference between the market value of the organization and the book value, as it is a knowledge and intellectual balance that is not announced in the annual lists of organizations (Shabwi \& Bin Al-Kahl, 2019).

Al-Sudani and Al-Salman (2019) define intellectual capital as all that an organization possesses of intangible knowledge assets and core capabilities that invest in it leads to achieving sustainable competitive advantage and creating added value to its products. Zawawi and Bin 
Khadija (2017) also defined that it includes various tangible and intangible assets. The tangible assets created by individual and collective practices, for the purpose of building competencies and skills, allowing assets to create added value, and intellectual capital is considered one of the most valuable assets at the present time, because it represents a scientific intellectual ability capable of making changes, modifications and adaptations to the surrounding environmental changes, and what it is witnessing organizations are one of the challenges of globalization, intense competition, global transformation towards a knowledge economy, and global technological development, which directed organizations to the need to invest in human and knowledge resources, as it represents the real capital on which the success or failure of organizations depends (Al-Sudani \& Al-Salman, 2019).

There is agreement among many researchers about defining the dimensions of intellectual capital, as it has been identified in three dimensions: human capital, structural capital, and relational capital (Stewart, 1999, 11; Simina, 2021; Pap et al., 2020; Ginesti \& Ossori, 2020; Zhang et al., 2021).

1. Human Capital: given the modern business environment of development, permanent change, and an increase in competition, which has multiple sources and forms, institutions must adopt the best option to ensure growth and expansion. Therefore, it is necessary to consider workers as one of the core capabilities in organizations that give great competitive value, especially if they have a range of capabilities and skills in decision-making processes and creativity in ways that cannot be imitated by competing organizations (Al-Zubaidi \& AlMashhadani, 2016).

Since the beginning of the twentieth century, organizations have begun to view human beings as an important capital that should be invested in order to benefit from their ability and constructive skills, and their knowledge in creativity, discovery and development, as is the case with physical capital, as the human element is the main element in the economic process, it is the producer and consumer element, and it is called It has the societal human capital, which he represented as the sum of human energies that can be invested and used to obtain economic resources (Al-Anzi \& Saleh, 2008, 267).

Human capital is the intangible value found in individual competencies, and it is the necessary process for mobilizing and developing human capabilities and competencies, which, leads to providing man with resources that increase his knowledge, knowledge and capabilities, which increases his energies and production capabilities. The concept of human capital is one of the urgent strategic issues. Because of the important role it plays in the long-term technical and economic progress, where human capital is one of the basic measures against which the wealth of nations is measured, because capital is considered the basis that influences the economic and social situation and determines the progress of countries (Al-Anzi \& Saleh, 2008, 267).

Human capital was defined as an increase in knowledge, skills and capabilities, which leads to the accumulation of human capital and its investment in the development of the economic system and the development of skills that are reflected on work capabilities and lead to increased production (Abdualdaem, 2021). Al-Zubaidi and Al-Mashhadani (2016) defined it as capabilities, skills and experiences and the knowledge owned by the organization's members, which is a real wealth and an important resource, to work on investing it in the optimal way in order to achieve distinct levels of performance. 
2. Structural Capital: structural capital includes the group of sub-systems that represent the organizational structure of the organization and the organizational and structural capabilities and infrastructure assets, as it is seen as the basic structure that enables human capital to work, innovate, achieve and benefit from its maximum potential, and it includes traditional properties from buildings, machines, software, patents, trademarks, manufacturing methods and relationships with customers, it also includes culture, organizational processes, procedures and operations (Isawy \& El-Tahhan, 2018), and it consists of external structural capital, which attracts and motivates individuals outside the organization, and internal structural capital, which includes everything relates to the efficiency of the internal processes of patenting and brand management (Najm, 2019, 147).

Hubert (1996) showed that the structural capital in any organization consists of the following elements:

- Systems: it is the way through which the operations within the organization (such as information and communications) are carried out.

- Structure: the arrangement of the powers and responsibilities of the individuals working within the organization.

- Strategy: it is the organization's goals and the means that can help in achieving these goals.

- Culture: it includes the sum total of the opinions and ideas of the employees within the organization.

3. Relational Capital: it refers to the resources associated with the organization's external and internal relations with customers, suppliers and partners, capable of generating value for the organization. This dimension refers to the strength of the relationship with customers and their satisfaction with the organization, performance, and speed of access to them. The importance of relational capital is that it is a measure of the knowledge that customers have about the organization, so that this knowledge ensures maintaining their loyalty and satisfaction, and it is an indicator of the organization's ability to adapt to the external environment, identify the needs and desires of customers, and the organization's ability to maintain and expand its market share (Isawy \& El-Tahan, 2018). Relational capital represents the sources of knowledge derived through the network of relationships, and there are those who see it as the value derived from satisfied loyal customers, suppliers, relationships with governmental and non-governmental agencies and any other external sources that affect the performance of the organization (Vanlyl, 2005).

\section{Smart Organization}

Given what the world is witnessing from an accelerating technological race through technological challenges, such as globalization, the knowledge revolution, and information technology, organizations have been placed in a very accelerating technological race, which has increased their responsibility to adopt the latest technological forces and modern administrative methods. The need to bring about radical changes in the ways its thinking, to ensure its sustainability and work to achieve a competitive advantage, came the smart organization that calls for continuous learning, adaptation to environmental variables, knowledge generation and management, orientation towards intellectual capital and interest in the knowledge industry, as these forces are considered the most important elements of production that directly affect the success of organizations or their failure (Al-Wadi \& AlSobbah, 2020). 
Given the need for organizations to increase the pace of learning, to be able to keep pace with changes in the contemporary business environment, and to achieve this, they need more openness and receive new ideas and concepts. They also need to invent new goods, services, and methods, and train workers and encourage them to take initiative and innovate while doing their work. Because the commitment to achieving the goals of organizations is the source of values and a driver for the behavior of managers, the emphasis of thinkers and leaders of organizations on the use of knowledge and skills by workers, as well as the use of their intelligence will lead to their organizations reaching the top and excellence (smart organization), hence the importance of addressing the contents of smart organizations. In the business environment in order to achieve adaptation to the environment that enables growth and sustainability, and because the leaders of organizations possess leadership competencies, which is one of the pillars that contribute to the development of their organizations to deliver and transform them into smart organizations that play a pivotal role in achieving excellence and excellence in the long run (Al-Zoubi \& Al-Nasra, 2019; 124).

The concept of the smart organization appeared at the end of the last century, specifically in the year 1997. The concept of the smart organization is a new concept in contemporary management thought, which was based on the principle of organizations that encourage learning, development and training. The concept of smart organizations has received great attention in recent times, as it is applied to various organizations in various fields that seek to change the way they conduct their business (Al-Wadi \& Al-Sobbah, 2020).

Al-Qadi and Abu Bakr (2021) defined the smart organization as the organization that has the ability to learn, change and adapt to emergency and emerging environmental changes, the ability to successfully face challenges, and the ability to link the elements of information management to learning so that it has the ability to make the right strategic decisions, in order to seizing opportunities and achieving the value necessary for their sustainability and their survival on the path of acting intelligently. Al-Wadi and Al-Sobbah (2020) defined the smart organization as a social unit that depends primarily on the knowledge industry and the intellectual capital that characterizes the human cadre. Through the smart cadre that the organization enjoys, it can employ the rest Technological, material and financial resources in the correct manner, which enables them to keep pace with changes and adapt to them and increase the ability to continuous learning within the organization. On the other hand, AlAnazi and Saleh $(2008,172)$ define them as organizations that are interested in investing in human talent and information technology through an institutional value system that depends on Transparency, creativity and respect.

As for Beuses (2019), he showed that the smart organization is the organization that has the ability to solve problems and make creative decisions in the least time and cost, using the available resources of information, knowledge, human and financial sources, through continuous learning and training processes to build capacity for employees and use internal and external information and address it to build knowledge of the organization, through the organization's acquisition of sufficient flexibility to adapt to environmental changes and developments, and subject workers to continuous education and training processes.

The dimensions of the smart organization differ according to different researchers and their opinions, and according to the different goals that they seek to achieve from their studies and research. Here, the dimensions of the smart organization that were adopted in this study will be reviewed. 
1. Environment Understanding: scientific experiences have proven that organizations do not arise out of a vacuum, but are born to meet the needs of the society in which they are located. It is complete and continuous with the changes that occur in the surrounding environment, as it determines the opportunities that must be seized and the threats that must be avoided (Kazim et al., 2020).

The concept of the environment includes everything that is inside and outside the framework of the organization, including the social, economic, political, legal, cultural, social, natural, psychological and international conditions in which the organization operates, including the internal organizational climate of the organization from management, workers, financial and human capabilities, and all parties related to the organization from the beneficiaries, official and governmental bodies, pressure groups, trade unions, and chambers of commerce and industry, as it includes all internal and external dimensions of the organization. The environment represents a set of factors, dimensions and components that affect administrative, organizational and strategic practices, and requires the smart organization to work on understanding these dimensions with all their overlaps, details and interactions, and that it has the ability to interact and deal with it in a balanced and dynamic manner, which qualifies the organization to achieve the best results. The smart organization has as a main advantage the ability to immediately adapt to the social and economic reality in which it operates, and its ability to respond to changes in the surrounding environment through the use of information and communication technology that operates. It improves internal processes, accelerating its ability to innovation in the goods product provided and increases their competitiveness (Mesaada, 2013).

The understanding of the environment includes three elements, which are (Al-Sharafi, 2020): - Accommodating uncertainties: it is the process of the intelligent organization's employees understanding the uncertainties in the future realistically, and the ability to deal with them, manage the risks associated with them, and take them into consideration in the management decision-making process.

- The strategic perspective from the outside to the inside: the smart organization works on evaluating its current position and thinking about its future position, by understanding the external environment in all its details, and accordingly, it works internally to achieve its strategic objectives.

- Systemic thinking: it is the comprehensive systematic thinking of the interrelationships in the organization, to deal strategically in a highly competitive environment, as a result of the development of technology, products and processes.

2. Continuoes Learning: continuous organizational changes have created the need for continuous learning environments that support the self-development of its employees by providing continuous training, development and education processes for employees and necessary for development. Its ability to face various environmental challenges and changes and the ability to respond to them effectively generates an added value for the organization. Continuous learning by the organization and its members makes it more capable in facing changes and how to deal with them, reducing resistance to change and increasing the mobilization and development of human energies (Beuses, 2019). Continuing education means training for change, and working to promote self-learning, at the level of the individual, group or organization as a whole. More information about the organization's surrounding environment, and how to deal with it, whether this information belongs to customers or suppliers, suppliers or markets, and employ this information in an effective manner for the 
continuous improvement of processes and products through the mobilization and development of human energies, and the mobilization of the energies of the environment and benefiting from it through the preparation of organizational plans and programs, which have a fundamental role in achieving the desired goals and thus increasing the organization's ability to improve production and increasing its market share (Al-Zoubi \& Al-Qaid, 2017).

From the point of view of Al-Sharafi (2020), continuous learning means the continuity of acquiring opportunities, knowledge and new skills constantly and in different ways, such as training, development, lectures, seminars, reading, following up on competing organizations in the market and working to benefit from their experiences, in light of rapid technological progress, rapid competition, and global changes.

3. Find Strategic Alternatives: the smart organization works on developing new methods, procedures, options and ways of working that enable the organization to meet its needs and implement its strategies. Providing strategic alternatives enables the organization to create new opportunities. Forecasting the results of each strategy, which enables the organization to use these expected results and integrate them with the organization's goals, and thus achieve them in a manner appropriate to the surrounding environment and the available resources (Al-Ariki, 2018).

4. Adaptation: organizations work in a contemporary environment characterized by continuous change, so the organization is keen to confront these changes through the processes of adaptation and rapid response to them, in order to ensure their survival and permanence (Beuses, 2019). The stability and survival of organizations is based on their ability to respond to changes taking advantage of opportunities and confronting threats in the surrounding environment, business organizations often work in an environment characterized by uncertainty, and therefore need constant and continuous monitoring and evaluation of the environment, to understand its sudden changes and requirements and thus respond quickly to them. One of the most important reasons for the organization to achieve survival and high profits is the correct understanding of market requirements It is one of the elements of understanding the environment and adapting to it (Al-Wadi \& Sobbah, 2020).

Organizational adaptation is considered an essential source for all business organizations, and contributes to setting goals in light of the internal and external environment, and in achieving distinctive capabilities that help the organization achieve its goals (Matheson \& Matheson, 2016).

5. Collective Intelligence: the successful leader is the leader who is able to direct and manage his work team. The work team and the group are the basis of any work, whether this work is economic, social or political. When talking about collective intelligence in teams and organizations, many focus there are researchers on collective intelligence, knowledge management and innovation processes, because of the important role they play in the rapidly changing world, and if knowledge management and collective intelligence are used by organizations as support for the innovation process, more efficient results can be achieved, saving organizations time and money, and is considered a decisive incentive efforts to enhance the efficiency and effectiveness of learning (Vengerov, 2011).

Matheson and Matheson (2016) indicate that smart organization is the organization that can improve its performance when it understands its dynamics and interactions necessary to bring about the required change in it, and this requires a change in the principles and culture 
of the organization, its habits and systems and focus on the talents, creativity and innovation of employees, in order to achieve change in the strategic decisions of the organization Thus improving its performance

\section{Relationship between Intellectual Capital and Smart Organization}

The application and practice of the dimensions of intellectual capital with its three components (human, structural and relational), focusing on human capital, has a significant role in achieving the dimensions of smart organizations (resource management, understanding the environment, and achieving organizational goals), with a detailed explanation of the impact of understanding the environment on achieving organizational goals, as it requires focusing on human capital in the organization and working to empower workers to carry out their work by making appropriate decisions related to the powers required by their work, as well as participating in decision-making related to setting priorities for investment in its various resources, as well as the participation of And the flow of information related to performance, organization, and obtaining satisfactory results for internal and external customers (Al-Zoubi, 2020).

\section{Literature Review}

Al-Qadi and Abu Bakr's study (2021) focused on measuring the impact of strategic management with its dimensions (environmental survey, strategy formulation, strategy implementation, control and evaluation) in the smart organization with its dimensions (continuous learning, adaptation, and collective intelligence), as well as testing the impact of strategic leadership in modifying the impact of management strategy in the smart organization. The study showed a set of results, the most important of which are: there is an impact of strategic management in building the smart organization, and this effect has increased in light of the presence of strategic leadership as a modified variable, and the results of the descriptive analysis of the dimensions of the smart organization (continuous learning, adaptation, and collective intelligence) showed that companies pay attention to great for the dimensions of the smart organization in varying proportions, where collective intelligence obtained the highest level of importance, and this indicates that companies depend on the collective energies and capabilities of their work teams, in addition to making efforts that enable them to encourage and attract creative ideas to their cadres, and crystallize this in improving performance levels and raising the level of the quality of the work mechanism, which would improve the reputation, continuity and survival of pharmaceutical companies with customers in the market despite the intensity of competition, as well as the extent to which companies are interested in diagnosing environmental factors and understanding the market, which enabled them to reduce risks resulting from randomness and ambiguity and increase their ability to adaptation, and the results showed a high level of companies' interest in developing and educating their employees in order to generate added value for their clients, and to effect positive chang in future strategic scenarios. On the other hand, Khaddam et al (2020) study focused on identifying the impact of human resource management strategies in smart organizations in terms of their dimensions (understanding the environment, finding strategic alternatives, continuous learning, smart operations, and social intelligence), and the modified role of enabling staff. One of the most prominent findings of the study is that there is an impact of human resource strategies in smart organizations, and that strategies for recruitment, recruitment and motivation contribute directly to influencing smart organizations, while strategies for development, training and performance evaluation 
support other human resources strategies to achieve their impact in smart organizations and do not directly contribute to Influencing them, and empowering workers contributes to modifying the impact of human resource management strategies in smart organizations.

In another study conducted by Al-Zoubi (2020), in which he tried to verify the impact of talent management strategies in the smart organization, while examining the mediating role of intellectual capital. The results of the study indicated that the levels of relative importance of the dimensions of the smart organization (resource management, understanding the environment, and achieving organizational goals) were varied between high for resource management and medium for understanding the environment, and achieving strategic goals, and in total for all dimensions came medium, and there was a statistically significant effect of talent management strategies Its dimensions in the smart organization, and the presence of a statistically significant effect of talent management strategies in terms of their combined dimensions in the smart organization through intellectual capital. As for the study of Al-Naimi et al (2020), it aimed to know the impact of the application of total quality management in the smart organization. The study found the availability of dimensions of organizational intelligence related to the axis of strategic and in-depth vision, the ability of computer information systems companies to predict clear visions of their future in the unstable and surrounding business environment, the ability of companies to use and obtain the available knowledge, and the ease of knowledge flow between administrative levels, with the availability of a culture Share knowledge among employees, support information systems in companies for the process of flow, flow and dissemination of knowledge among employees, and provide dimensions of organizational intelligence related to the following axes; emotionally raising the employees in the companies investigated and the employees' desire for teamwork, and their belief in the company's goals and striving to achieve them.

The study of Al-Wadi and Al-Sobbah (2020) focused on identifying the extent of the impact of cloud management on the development of the smart organization in its dimensions (environmental adaptation, continuous learning, and knowledge transfer), in addition to building a theoretical framework that clarifies the concept of cloud management and a statement of its most important pillars, and recognition of its importance in the development of the smart organization. And the extent of its importance in building a modern and advanced country, in addition to identifying the characteristics and dimensions on which smart organizations are based to be strengthened by cloud management. The results of the study showed that the cloud management was of a high level, in addition to the high level of development of the smart organization, and it was found that there is a strong statistically significant correlation between cloud management with its dimensions (process automation, information security, performance monitoring) and the development of the smart organization with its dimensions (continuous learning, adaptation environmental, and knowledge transfer), and that continuous learning was the most important, followed by the transfer of knowledge, and finally environmental adaptation.

The study of Wali and Abdullah (2020) aimed to test a set of dimensions of the smart organization and its role in talent management. The results of the study showed that there are statistically significant differences towards the dimensions of the smart organization and the dimensions of talent management, and that the smart organization is able to achieve success for talent management in organizations. The respondents agreed that the smart organization and its dimensions came with a higher order of importance than talent management, and this confirms the priority of the smart organization. The study of Radi et al (2018) focused on recognizing the level of application of the dimensions of the smart 
organization, the level of their achievement of the characteristics of technical innovation, and determining the role of the smart organization in creating technical innovation. The study concluded that the level of application of the concept of the smart organization was medium, and there is an impact of the smart organization in creating technical creativity, and a significant

\section{Study Hypothesis}

Based on the question of the study and their objectives, the following hypothesis can be determined:

$\mathrm{H}$ : There is impact of intellectual capital on smart organization at AlBashir Hospital.

\section{Methodology}

\section{- Population and Sample}

The study population consisted of managers at AlBashir Hospital at at the upper and middle levels, and their number was (204). The researchers used the comprehensive survey method for managers through a questionnaire. After distributing the electronic questionnaire that was developed for this purpose, (103) valid questionnaires were retrieved for statistical analysis.

\section{Study Tool}

In this study, the researchers relied on the electronic questionnaire in collecting data from the managers of the study population. The questionnaire consisted of two sections:

Section one: this section consists of items that measure intellectual capital. The items of this section have been developed on the following studies: Al-Samarrai, 2019; Abdul Hamid, 2020; Alawneh and Hawamdeh, 2021; Abd, 2020; Zubaidi, 2016.

Section two: this section consists of items that measure smart organization. The items of this section have been developed on the following studies: Al-Qadi \& Abu Bakr, 2021; Al Wadi \& Asbah, 2020.

The five-point scale was adopted to answer the items of the study tool, which ranged between strongly agree (5) points, and strongly disagree (1) one point.

\section{Results}

The results of the analysis in Table 1 indicate that there are medium levels for the dimensions of intellectual capital (independent variable), the mean values ranged between 3.47-3.56, while the mean values for the dimensions of smart organization ranged between 3.40-3.53. As for the dimensional reliability coefficient of the two variables, it exceeded the specified minimum value of 0.70 , which ranged between $0.88-0.93$. 
Table 1 results of descriptive analysis

\begin{tabular}{cccccc}
\hline$\#$ & Variable & Items & Alpha & Mean & Std. \\
\hline 1 & Human capital & 5 & 0.91 & 3.56 & 0.91 \\
2 & Structural Capital & 5 & 0.88 & 3.54 & 0.83 \\
3 & Relational capital & 5 & 0.88 & 3.47 & 0.89 \\
4 & Enviroment understanding & 5 & 0.93 & 3.53 & 0.85 \\
5 & Continoues learning & 5 & 0.92 & 3.53 & 0.87 \\
6 & Find strategic alternatives & 5 & 0.92 & 3.53 & 0.85 \\
7 & Adaptation & 5 & 0.93 & 3.40 & 0.89 \\
8 & Collective intelligence & 5 & 0.91 & 3.44 & 0.85 \\
\hline
\end{tabular}

Table 2 presents the results of analyzing the impact of intellectual capital on smart organization, as the results showed that there is a significant impact of intellectual capital on smart organization, the value of $\mathrm{R}^{2}=0.76$ and with a level of significance of 0.00 , which means that the discrepancy in the smart organization is due to $76 \%$ of the capital intellectual. The results in the table indicate that the reason for this impact is due to relational capital and structural capital, while human capital had no significant impact.

Table 2 impact of intellectual capital on smart organization

\begin{tabular}{|c|c|c|c|}
\hline Variable & B & $\mathrm{T}$ & Sig. \\
\hline Communication & 0.09 & 1.14 & 0.26 \\
\hline Time management & 0.38 & 4.44 & 0.00 \\
\hline Leadership & 0.39 & 4.22 & 0.00 \\
\hline$R^{2}=0.76$ & & Sig. $=0.00$ & \\
\hline
\end{tabular}

Table 3 indicates the sequence of the impact of dimensions of intellectual capital on smart organization, where it appeared in model 1 that the relational capital is the most influential on smart organization. The value of $\mathrm{R}^{2}=0.68$, this means that the ratio of the influence of the relational capital on smart organization is $68 \%$. In model 2 , after adding the structural capital to the relational capital, the impact ratio of two dimensions increased to become $\mathrm{R}^{2}=0.74$, i.e. by $0.74 \%$. On the other hand, the results of the stepwise regression analysis indicated that the impact of human capital on smart organization was not significant. This means that the sequence of dimensions of intellectual capital in terms of its strength on smart organization was in the first place for relational capital and then for structural capital.

Table 3 stepwise impact of intellectual capital on smart organization

\begin{tabular}{cccccccc}
\hline Model & Variable & $\mathrm{B}$ & $\mathrm{T}$ & $\mathrm{Sig}$. & $\mathrm{R}^{2}$ & $\mathrm{~F}$ & Sig. \\
\hline 1 & Relational capital & 0.75 & 14.68 & 0.00 & 0.68 & 215.79 & 0.00 \\
2 & Relational capital & 0.44 & 5.68 & 0.00 & 0.74 & 143.33 & 0.00 \\
& Strutural capital & 0.40 & 4.83 & 0.00 & & & \\
\hline
\end{tabular}

\section{Discussion}

The study results indicate that there are medium levels of the dimensions of intellectual capital, where human capital took precedence in a relative manner compared to structural capital and relational capital. This means that the relationship of AlBashir Hospital with stakeholders (suppliers, customers, employees and competitors) is not at the required level, and so on. With regard to structural capital, the regulations, laws, and procedures do not have sufficient flexibility for the hospital's response to environmental changes, and less so in relation to human capital, whose level was better than the previous two dimensions. It 
appears that the hospital administration has medium-level professional expertise, but it needs more attention to the experiences, skills and knowledge of its employees. The hospital also needs to focus its attention on building better relationships with stakeholders, which would help in solving many of the problems that it may face, in addition to rethinking the design of systems, laws and procedures and making them more flexible, whether for employees or clients.

There are medium levels of the dimensions of the smart organization. The results indicated the inability of the hospital to adapt as necessary to the requirements of the environment in which it operates, as the hospital is unable to respond appropriately to the changes taking place in the environment. Thusm with regard to the ability of hospital staff to work in a team manner in an effort to increase their knowledge, which can lead to a lot of creative ideas that can be translated into new services. On the other hand, the hospital's understanding of the environment, finding strategic alternatives and continuous learning was better than its ability to adapt and work together. However, the level was not at the expected level. The hospital in general understands the needs of the community in which it is located, and there is a desire by the hospital staff to gain experiences and modern skills and knowledge in order to meet challenges through self-learning and continuous improvement. The hospital needs a greater understanding of the environment in which it operates, by seeking continuous learning from its experiences and the experiences of others and benefiting from teamwork based on cooperation as an alternative to competition in an effort to adapt to the changes that are taking place in the external environment.

There is a significant impact of intellectual capital on the hospital's ability to be a smart organization, as the hospital's possession of good relations with stakeholders and its possession of a flexible organizational structure capable of responding to changes in the work environment, and its possession of workers with expertise and skills, all lead to its ability on understanding the economic and social conditions, and the ability to positively interact with the environment, which leads to the hospital's ability to exploit the opportunities that appear in the environment, as well as the possibility of workers to find appropriate strategic alternatives using their skills and experience.

The most influential dimensions of intellectual capital for the hospital to be a smart organization is the relational capital. This indicates that the new relationship between the hospital and stakeholders and the extent of satisfaction of the parties it deals with makes the hospital more able to understand the environment and ease of dealing with it. Structural capital comes in second place in terms of its impact on building a smart hospital. The more flexible the organizational structure in terms of regulations, laws, and procedures, the more it gives the hospital the ability to understand the environment and adapt to the changes that occur in it.

\section{Referencess}

Bdualdaem, A. (2021). The Effect of Intellectual Capital on the Total Quality Management of Higher Education and Scientific Research Institutions in Baghdad. Journal of Economics and Administrative Sciences, 27(127), 75-97.

Al-Anazi, S., \& Saleh, A. (2008). Intellectual capital management in business organizations. Al-Yazuri Scientific Publishing and Distribution House.

Al-Ariki, M. (2018). Strategic management. Al-Ameen for Publishing and Distribution.

Al-Naimi, M., Al-Shura, A., \& Al-Tarawneh, R. (2020). The impact of the application of total quality management in the smart organization: an applied study in computer 
information systems companies. Global Journal of Economics and Business, 8(2), 293307. https://doi.org/10.31559/GJEB2020.8.2.8

Al-Qadi, S., \& Abu Bakr, S. (2021). The impact of strategic management on building a smart organization: The modified role of strategic leadership in Jordanian pharmaceutical companies. Global Journal of Economics and Business, 10(2), (259-284). DOI: https://doi.org/10.31559/GJEB2021.10.2.3

Al-Sharafi, S. (2020). Improvement according to (ISO 9001:2015) and its role in building the smart organization: A case study of the Palestinian Telecom Group companies. Journal of Management and Economics Research, 2(3), (63-77), https://doi.org/10.48100/merj.v2i3 .110

Al-Sudani, A., \& Salman, R. (2019). Formulating a strategic scenario for construction laboratories based on intellectual capital. Anbar University Journal of Economic and Administrative Sciences, 11(24), (236-264).

Al-Wadi, H., \& Al-Sobbah, H. (2020). The impact of cloud management on the development of the smart organization: a case study of the Kuwaiti Ministry of Health. Global Journal of Economics and Business, 8(3), (548-65). DOI: https://doi.org/10.31559/GJEB2020.8.3.14.

Al-Zoubi, F., \& Al-Qaid, M. (2017). The impact of the training management strategy in smart organizations: the mediating role of e-learning: an applied study in the pharmaceutical industry listed on the Amman Stock Exchange. Mithqal Journal of Economic and Administrative Sciences, 3(2), (273-310).

Al-Zoubi, H., \& Al-Nawasra, M. (2019). Smart organizations: A strategic perspective. Dar Wael for printing, publishing and distribution.

Al-Zoubi, M. (2020). The impact of talent management strategies in smart organizations: the mediating role of intellectual capital in Hamad Medical Corporation in Qatar. Unpublished doctoral thesis, International University of Islamic Sciences, Amman, Jordan.

Al-Zubaidi, G., \& Al-Mashhadani, A. (2016). The role of human capital and the outstanding performance of workers in achieving organizational excellence, a field research in the Iraqi Ministry of Oil. Al-Ghari Journal of Economic and Administrative Sciences, 13(38), (269-287).

Beuses, A. (2019). Incidence of smart organizations in knowledge management incidence of intelligent organizations in the management of knowledge. Koinonía Interdisciplinary, 8(4), http://dx.doi.org/10.35381/rkv4i8.283.

Ginesti, G., \& Ossori, M. (2020). The influence of family-related factors on intellectual capital performance in family businesses. Journal of Management and Governance, (25), 535560.

Hubert, S. (1996). Tacit knowledge: The key to the strategic alignment of intellectual capital. Strategy and Leadership, 24(2), 10-14.

Isawy, N., \& El-Tahan, I. (2018). Intellectual capital as an intermediate variable between the quality of work life and Six Sigma methodology applied to workers in the Ministry of Health in the Kingdom of Saudi Arabia. Arab Journal of Management, 38(3), 189-214.

Kazem, J., Al-Attar, F., \& Al-Yasiri, A. (2020). The effect of adopting the smart organization model in achieving outstanding strategic performance: An exploratory research of the opinions of a sample of managers in mobile telecommunications companies in Iraq (Zain Iraq - Cork - Basic). Al-Muthanna Journal of Administrative and Economic Sciences, 10(3), (60-79). 
Khaddam, A., Artima, H., \& Badr, B. (2020). Human resource management strategies and their impact on smart organizations modified role: Empowering workers (a field study: on a group of pharmacies operating in the capital Amman governorate). Globall Journal of Economics and Business, 8(1), 117-148. DOI: https://doi. org/10.31559/GJEB2020.8.1.10

Matheson, D., \& Matheson, J. (2016). Smart organizations perform better. ResearchTechnology Manghement, 4(44), 49-54, https://doi.org/10.1080/08956308.2001.11671442

Mesaada, M. (2013). Organization management a holistic perspective. Dar march publishing, distribution and printing.

Najm, A. (2019). The management of tangibles: The management of the immeasurable. Dar Al-Yazuri for Publishing and Distribution.

Pap, E., Petković, M., \& Simićević, A. (2020). Measuring distribution of intellectual capital components contribution: French context. The European Journal of Applied Economics. 18(1), 1-14.

Radi, M., Abu Shamala, D., \& Haniyeh, Sh. (2018). The reality of applying the dimensions of the smart organization and its relationship to the level of technical creativity at the Palestine Technical College in Deir Al-Balah from the point of view of its employees. Arab Journal for Quality Assurance of University Education, 11(36), (76-110). https://doi.org/10.20428/AJQAHE.11.36.4

Shabwi, S., \& Ben Lakhal, N. (2019). Intellectual capital as a mechanism for achieving distinguished university performance: a sample current study in the university pole schools in Kleia. Journal of Strategy and Development, 9(3), (426-450).

Simina, A. (2021). How intellectual capital is made. Studies in buisness and economic, 16(1), Doi: $10.2478 /$ sbe-2021001.

Stewart, A. (1999). Intellectual capital: The new wealth of organization. Doubleday publishing Group.

Vanlyl, R. (2005). Structural capital management creates sustainable competitiveness and prolonget first-mover advantage. Intellectual Capital Management Series, 3(3), 85-98.

Vengerov, A. (2011). Collective learning and collective intelligence working together. International Journal of Learning, 18(2), 45-56, https://doi.org/10.18848/14479494/cgp/v18i02/47500.

Wali, A., \& Abdullah, N. (2020). The role of some dimensions of the smart organization in enhancing talent management processes: an analytical study of the opinions of managers of a sample of private hospitals in the city of Erbil. Zanst Scientific Journal, 5(1), 26-51.DOI: 10.25212/Ifu.qzj

Zawawi, K., \& Ben Khadija, M. (2017). The role of e-learning in developing the intellectual capital of economic institutions: a field study of some institutions in Setif. Economic Visions Journal, 7(2), (235-247).

Zhang, Z., Yu, Q., Jin, Z., \& Xu, J. (2021). Do intellectual capital elements spur firm performance? Evidence from the textile and apparel industry in China. Hindawi Limited, 2021, https://doi.org/10.1155/2021/7332885 